\title{
Formoterol thrice weekly does not result in the development of tolerance to bronchoprotection
}

\author{
Beth E Davis BSc, John K Reid MD FRCPC, Donald W Cockcroft MD FRCPC
}

BE Davis, JK Reid, DW Cockcroft. Formoterol thrice weekly does not result in the development of tolerance to bronchoprotection. Can Respir J 2003;10(1):23-26.

BACKGROUND: Loss of bronchoprotection routinely follows regular treatment with beta ${ }_{2}$-agonists. There are no data on the effects on bronchoprotection for thrice weekly use of a beta ${ }_{2}$-agonist.

METHODS: A double-blind, randomized, placebo controlled crossover trial was conducted to investigate the effects of thrice weekly administration of $12 \mu \mathrm{g}$ of formoterol versus placebo on bronchoprotection against methacholine. As an expected positive control, formoterol $12 \mu \mathrm{g}$ once daily was also evaluated.

RESULTS: There was no significant difference versus placebo in the bronchoprotective effects of $12 \mu \mathrm{g}$ of formoterol administered on day 8 , following daily treatment for seven days or treatment every other day (analysis of variance $\mathrm{P}=0.34$ ). However, a nonsignificant trend towards lower concentration of methacholine that caused a $20 \%$ fall in forced expiratory volume in $1 \mathrm{~s}$ developed only following the daily formoterol dosing.

CONCLUSIONS: Thrice weekly dosing does not result in the development of tolerance to bronchoprotection against the direct acting stimulus methacholine.

Key Words: Bronchoprotection; Formoterol

\section{Le formotérol trois fois par semaine ne provoque pas une tolérance à la bronchoprotection}

HISTORIQUE : Une perte de bronchoprotection suit invariablement un traitement régulier aux béta ${ }_{2}$-agonistes. Aucune donnée ne porte sur les effets de l'usage, trois fois par semaine, des béta ${ }_{2}$-agonistes sur la bronchoprotection.

MÉTHODOLOGIE : Un essai croisé à double insu, aléatoire et contrôlé contre placebo a été mené pour explorer les effets, sur la bronchoprotection contre la méthacholine, de l'administration de $12 \mu \mathrm{g}$ de formotérol trois fois par semaine par rapport à un placebo. Afin d'obtenir un contrôle dont on prévoyait le résultat positif, l'administration quotidienne de $12 \mu \mathrm{g}$ de formotérol a également été évaluée.

RÉSULTATS : Par rapport au placebo, $12 \mu \mathrm{g}$ de formotérol administrés le huitième jour suivant un traitement quotidien pendant sept jours ou un traitement tous les deux jours (analyse de variance, $\mathrm{P}=0,34$ ), ne modifiaient pas les effets bronchoprotecteurs de manière significative. Cependant, une tendance non significative vers une concentration plus faible de méthacholine, qui provoquait une chute de $20 \%$ du volume expiratoire forcé en $1 \mathrm{~s}$, se présentait après le dosage quotidien de formotérol seulement.

CONCLUSIONS : Une dose trois fois par semaine n'entraîne pas l'apparition d'une tolérance à la bronchoprotection contre la méthacholine par stimulation à action directe.
$\mathrm{T}$ olerance to the bronchoprotective effect of both long and

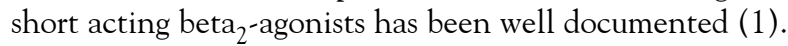
Researchers have shown that protection is lost rapidly at standard doses and has a greater effect against indirect than against direct stimuli.

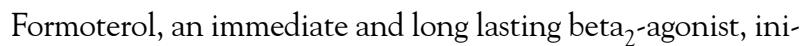
tially indicated as add-on therapy for patients whose lung function and symptoms are not adequately maintained with inhaled corticosteroid, has recently been approved as rescue therapy for acute bronchoconstriction. Like salbutamol, rescue use of formoterol is 'as needed' but should not exceed three times a week (2). At least one study has shown the development of tolerance with daily administration of $12 \mu \mathrm{g}$ of formoterol over a 14-day period (3). There are, however, no data determining the effects of thrice weekly administration. We therefore investigated thrice weekly administration of $12 \mu \mathrm{g}$ of formoterol versus placebo and included a daily $12 \mu \mathrm{g}$ treatment arm as an anticipated positive 'control' for the development of tolerance.

\section{Subjects}

\section{METHODS}

The study protocol was approved by the University of Saskatchewan BioMedical Ethics Committee, and 13 patients with mild to moderate asthma were enrolled into the study after providing consent and meeting eligibility criteria. Patients with a forced expiratory volume in $1 \mathrm{~s}\left(\mathrm{FEV}_{1}\right)$ of less than $65 \%$ of the predicted volume or a concentration of methacholine that causes a $20 \%$ fall in $\mathrm{FEV}_{1}\left(\mathrm{PC}_{20}\right)$ of more than $8 \mathrm{mg} / \mathrm{mL}$ were not eligible. In addition, subjects had to be free of an upper respiratory infection for more than six weeks. Short acting beta-agonists were withheld for more than one week before enrolment, and no subjects had been using long acting beta-agonists. Atopic subjects avoided known allergen exposure for more than four weeks before and throughout the trial. Two participants were using a stable dose of inhaled corticosteroid, which they were allowed to continue using at the same dose for the duration of the study.

Division of Respiratory Medicine, Department of Medicine, Royal University Hospital, Saskatoon, Saskatchewan

Correspondence and reprints: Dr Donald W Cockcroft, Division of Respiratory Medicine, Royal University Hospital, 103 Hospital Drive, Saskatoon, Saskatchewan S7N OW8. Telephone 306-966-8294, fax 306-966-8694, e-mail cockcroft@sask.usask.ca 
TABLE 1

Baseline demographics

\begin{tabular}{|c|c|c|c|c|c|c|c|c|c|}
\hline Subject & Sex & $\begin{array}{c}\text { Age } \\
\text { (years) }\end{array}$ & $\begin{array}{l}\text { Height } \\
(\mathrm{cm})\end{array}$ & Atopy & $\mathrm{FEV}_{1}(\mathrm{~L})$ & $\begin{array}{c}\mathrm{FEV}_{1} \\
\text { (\% predicted) }\end{array}$ & $\begin{array}{l}\text { Methacholine } \mathrm{PC}_{20} \\
(\mathrm{mg} / \mathrm{mL})\end{array}$ & $\begin{array}{l}\text { Concomitant } \\
\text { medications }\end{array}$ & Status \\
\hline 1 & $\mathrm{~F}$ & 36 & 168 & No & 3.01 & 93 & 5.0 & None & Complete \\
\hline 2 & $\mathrm{~F}$ & 24 & 163 & Yes & 2.77 & 82 & 0.27 & None & Withdrawn \\
\hline 3 & $M$ & 54 & 168 & Yes & 2.34 & 68 & 0.50 & None & Complete \\
\hline 4 & M & 21 & 180 & Yes & 4.62 & 106 & 0.25 & None & Complete \\
\hline 5 & M & 27 & 180 & Yes & 5.85 & 122 & 7.0 & None & Complete \\
\hline 6 & $\mathrm{~F}$ & 30 & 160 & Yes & 2.59 & 82 & 4.2 & None & Withdrawn \\
\hline 7 & M & 35 & 183 & Yes & 4.26 & 94 & 2.0 & None & Complete \\
\hline 8 & M & 27 & 180 & Yes & 4.03 & 92 & 0.25 & None & Complete \\
\hline 9 & M & 36 & 173 & Yes & 3.13 & 82 & 0.25 & FP $500 \mu \mathrm{g} /$ day & Complete \\
\hline 10 & $\mathrm{~F}$ & 17 & 163 & No & 2.98 & 96 & 3.6 & BD $200 \mu \mathrm{g} /$ day & Complete \\
\hline 11 & $\mathrm{~F}$ & 18 & 168 & Yes & 3.95 & 106 & 2.6 & None & Complete \\
\hline 12 & $\mathrm{~F}$ & 23 & 160 & Yes & 2.68 & 83 & 0.07 & None & Withdrawn \\
\hline 13 & M & 29 & 178 & Yes & 3.69 & 81 & 0.25 & None & Complete \\
\hline
\end{tabular}

BD Budesonide; F Female; FEV 1 Forced expiratory volume in 1s; FP Fluticasone propionate; $M$ Male; $P C_{20}$ Concentration of methacholine that causes a $20 \%$ fall in FEV 1

Methacholine bronchoprovocation challenge

Subjects underwent the tidal breathing method of Juniper et al (4). Briefly, subjects presented to the laboratory daily and were required to rest to ensure stable lung function. Three reproducible flow volume loops were then obtained according to the guidelines of the American Thoracic Society (5). Following diluent inhalation, doubling doses of methacholine were administered at 5 min intervals until $\mathrm{FEV}_{1}$ manoeuvres, obtained at 30 and $90 \mathrm{~s}$ after 2 min inhalations, fell by $17 \%$ or greater. The decrease from the lowest $\mathrm{FEV}_{1}$ after diluent inhalation to the lowest $\mathrm{FEV}_{1}$ after methacholine inhalation was calculated. If the fall was $17 \%, 18 \%$ or $19 \%$, then the $\mathrm{PC}_{20}$ was obtained by extrapolation using a single-point algebraic formula (6). If the fall was greater than $20 \%$, the $\mathrm{PC}_{20}$ was interpolated using the standard algebraic formula (7). Starting concentrations were identical within a given subject and were at least two concentrations below the known $\mathrm{PC}_{20}$ for a given subject. Bronchoconstriction was reversed with 20 to $40 \mu \mathrm{g}$ of ipratropium bromide; in some cases spontaneous reversal was preferred.

\section{Study design}

This was a double-blind, placebo controlled, randomized crossover trial. Three kits containing six blinded Turbuhalers (Astra Pharma, Mississauga), three for days 1, 3 and 5, and three for days 2, 4, 6 and 7 were prepared. Each kit contained three treatment regimens: formoterol plus formoterol; placebo plus placebo and formoterol (days 1, 3, 5); and placebo (days 2, 4, 6 and 7). Each treatment arm required visits to the laboratory at the same time of day $( \pm 1 \mathrm{~h})$ on days 1 through 5 and again on day 8 . Consistent with the authors' previous investigations of beta-agonist tolerance (1), the washout duration between treatment periods was a minimum of seven days. Each visit consisted of baseline $\mathrm{FEV}_{1}$ determination followed by administration of blinded study medication, with the exception of day 8 , on which $12 \mu \mathrm{g}$ of openlabel formoterol was administered. $\mathrm{FEV}_{1}$ was measured again 10 min after inhalation of blinded or unblinded (day 8) medication just before methacholine bronchoprovocation challenge. Subjects administered doses on their own on days 6 and 7 with a

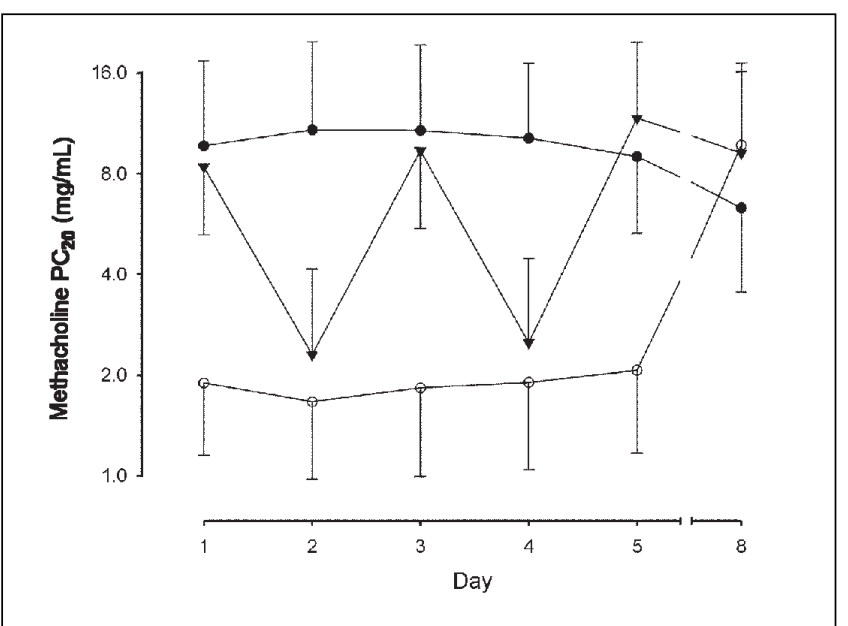

Figure 1) Geometric mean concentrations of methacholine that caused a $20 \%$ fall in forced expiratory volume in $1 \mathrm{~s}\left(\mathrm{PC}_{20}\right)$ for each treatment group (vertical axis) plotted for each day bronchoprovocation challenges were given (horizontal axis). Thrice weekly formoterol (closed triangle) $\mathrm{PC}_{20}$ values differed significantly from placebo treatment (open circles) on days 1, 3 and 5. Day $8 P_{20}$ values were not significantly different. Note, however, the trend toward the development of tolerance in the daily formoterol group (closed circles). Error bars represent SEM

blinded inhaler provided to them on leaving the laboratory on day 5 .

\section{Statistical analysis}

The primary end point, day 8 methacholine $\mathrm{PC}_{20}$, was analyzed using a two-way (subject versus treatment) analysis of variance (ANOVA) (STATISTIX for Windows, Analytical Software, USA). Least significant difference comparison of means was used when the ANOVA generated a $\mathrm{P}<0.05$. Secondary end points, baseline $\mathrm{FEV}_{1}$ and delta $\mathrm{FEV}_{1}$ after treatment, were analyzed in the same manner. A paired $t$ test was used for within-group post hoc analyses. This study had a greater than $90 \%$ power to detect a 0.5 concentration change in methacholine $\mathrm{PC}_{20}$. 
TABLE 2

Forced expiratory volume in the first second of exhalation $\left(\mathrm{FEV}_{1}\right)$ (mean $\pm \mathrm{SD}$ ) at baseline (before administration of $12 \mu \mathrm{g}$ formoterol) and $10 \mathrm{~min}$ after administration of $12 \mu \mathrm{g}$ formoterol, and the change in FEV $_{1}$ from baseline to 10 min after the dose (absolute D)

\begin{tabular}{|c|c|c|c|c|c|c|c|c|c|}
\hline \multirow[b]{2}{*}{ Day } & \multicolumn{3}{|c|}{ Placebo } & \multicolumn{3}{|c|}{ Daily formoterol } & \multicolumn{3}{|c|}{ Alternate day formoterol } \\
\hline & Baseline & 10 min after dose & Absolute $\Delta$ & Baseline & $10 \mathrm{~min}$ after dose & Absolute $\Delta$ & Baseline & 10 min after dose & Absolute $\Delta$ \\
\hline 1 & $3.73 \pm 0.97$ & $3.71 \pm 1.00$ & $-0.02 \pm 0.16$ & $3.75 \pm 0.93$ & $4.08 \pm 0.98^{*}$ & $0.34 \pm 0.18$ & $3.82 \pm 1.01$ & $4.07 \pm 1.02^{*}$ & $0.26 \pm 0.17$ \\
\hline 2 & $3.83 \pm 0.98$ & $3.78 \pm 0.94$ & $-0.05 \pm 0.08$ & $3.89 \pm 1.01$ & $4.05 \pm 1.01^{*}$ & $0.16 \pm 0.15$ & $3.93 \pm 1.00$ & $3.91 \pm 1.03$ & $-0.02 \pm 0.11$ \\
\hline 3 & $3.79 \pm 0.99$ & $3.74 \pm 1.02$ & $-0.04 \pm 0.13$ & $3.81 \pm 0.95$ & $4.07 \pm 1.00^{*}$ & $0.25 \pm 0.19$ & $3.80 \pm 0.98$ & $4.08 \pm 1.02^{*}$ & $0.28 \pm 0.16$ \\
\hline 4 & $3.73 \pm 0.96$ & $3.72 \pm 0.96$ & $-0.003 \pm 0.03$ & $3.85 \pm 0.97$ & $4.08 \pm 0.98^{*}$ & $0.21 \pm 0.21$ & $3.98 \pm 1.05$ & $3.99 \pm 1.02$ & $0.002 \pm 0.08$ \\
\hline 5 & $3.77 \pm 0.98$ & $3.72 \pm 0.98$ & $-0.06 \pm 0.10$ & $3.90 \pm 0.95$ & $4.12 \pm 0.99^{*}$ & $0.22 \pm 0.18$ & $3.79 \pm 1.01$ & $4.10 \pm 1.05^{\star}$ & $0.31 \pm 0.18$ \\
\hline 8 & $3.80 \pm 0.97$ & $4.05 \pm 0.99^{*}$ & $0.26 \pm 0.23$ & $3.76 \pm 0.96$ & $3.97 \pm 0.96^{*}$ & $0.21 \pm 0.17$ & $3.68 \pm 1.04$ & $4.00 \pm 1.02^{*}$ & $0.32 \pm 0.27$ \\
\hline
\end{tabular}

*12 $\mu \mathrm{g}$ formoterol

\section{RESULTS}

\section{Safety}

Thirteen subjects were enrolled (Table 1), 10 of whom completed the trial. One subject voluntarily withdrew before completing the second treatment arm because of the required time commitment, and two subjects were withdrawn because of worsening asthma. There were no other adverse events. Results are presented on 10 subjects with complete data.

\section{Bronchoprotection}

Daily geometric mean $\log \mathrm{PC}_{20}$ values for each treatment arm are shown in Figure 1. ANOVA of the primary end point showed no significant difference between the three treatment arms $(\mathrm{P}=0.34)$. Day 8 geometric mean $\mathrm{PC}_{20}$ concentrations were $6.3 \mathrm{mg} / \mathrm{mL}, 9.2 \mathrm{mg} / \mathrm{mL}$ and $9.6 \mathrm{mg} / \mathrm{mL}$ for daily formoterol, thrice weekly formoterol and placebo, respectively.

Both formoterol treatment arms were significantly greater than placebo on days 1,3 and 5 , and not significantly different from each other. On days 2 and 4, placebo and placebo days for the thrice weekly formoterol were significantly lower than daily formoterol but not significantly different from each other.

\section{Baseline $\mathrm{FEV}_{1}$}

The only significant difference (ANOVA, $\mathrm{P}=0.012$ ) was on day 4. The mean baseline $\mathrm{FEV}_{1}$ (Table 2) of the thrice weekly treatment arm $(3.98 \pm 1.05 \mathrm{~L}) 24 \mathrm{~h}$ after administration of $12 \mu \mathrm{g}$ formoterol (administered on day 3 ) was significantly greater than the mean for the placebo group $(3.73 \pm 0.96 \mathrm{~L})$. ANOVA for the analogous day 2 baseline $\mathrm{FEV}_{1}$ values indicated no significant difference between the three treatments $(\mathrm{P}=0.23$; paired $t$ test for placebo versus thrice weekly formoterol yielded $\mathrm{P}=0.092$ ).

\section{Bronchodilation}

ANOVA of day 8 mean daily absolute delta $\mathrm{FEV}_{1}\left(\mathrm{FEV}_{1}\right.$ 10 min after treatment minus baseline $\mathrm{FEV}_{1}$; Table 2) indicated a reduction in bronchodilation in the daily $(0.21 \pm 0.17 \mathrm{~L})$ versus the every other day treatment $(0.32 \pm 0.27 \mathrm{~L})$ at the 0.05 level. Subsequent paired $t$ test for day 1 versus day 8 for delta $\mathrm{FEV}_{1}$ within the daily treatment arm showed significant reduction in bronchodilation on day $8(\mathrm{P}=0.0035)$. There was, however, no significant difference in the post-formoterol $\mathrm{FEV}_{1}$ on day 8 (ANOVA $\mathrm{P}=0.62, \mathrm{FEV}_{1} 3.97$ to $4.05 \mathrm{~L}$ ).

\section{DISCUSSION}

In our study the long acting beta 2 -agonist formoterol taken once daily or once every other day over a seven-day period did not result in a loss of the protection afforded by a single $12 \mu \mathrm{g}$ dose against methacholine-induced bronchoconstriction. There is little in the literature with which to compare our findings; however, our findings do contradict the work of Lipworth et al (3), who found tolerance at various doses of formoterol, including $12 \mu \mathrm{g}$ administered once daily. Interestingly, the plot of our data for the daily formoterol group shown in Figure 1 develops a downward trend at day 4 and is lower by day 8 , but this was not statistically significant. The conflict between our results and those of Lipworth and colleagues may be explained by differences in the duration of treatment or the method of analysis. We administered a $12 \mu \mathrm{g}$ dose for seven days, compared with a $12 \mu \mathrm{g}$ dose for 14 days in the Lipworth et al study. At least one other seven-day investigation has failed to show tolerance despite the population being 'at risk' for its development and despite twice the daily dose of formoterol (8). We also chose between-treatment (formoterol versus placebo) protection afforded by formoterol as our primary end point, compared with a within-treatment first dose versus last dose comparison, as used by Lipworth and colleagues. The development of a downward trend of $\mathrm{PC}_{20}$ in our daily formoterol data may have significance with longer treatment duration, a larger sample size or both; a trend toward the loss of bronchoprotection following administration of $12 \mu \mathrm{g}$ formoterol twice a day for seven days has been previously documented (9). We did not consider concomitant administration or inconsistent administration of inhaled corticosteroid to be a contributing factor in the difference between our results and others' because inhaled corticosteroid administration does not prevent the development of tolerance (10), and oral prednisolone does not reverse established tolerance (11).

Our findings with respect to baseline $\mathrm{FEV}_{1}$ (Table 2) suggest improvements in daily lung function with thrice weekly dosing. Baseline $\mathrm{FEV}_{1}$ values for the every other day treatment arm deviate to significance from placebo on day 4. However, the same improvement was not evident on day 2 . This phenomenon is perhaps the result of prolonged or residual bronchodilator action from the previous day, suggesting that the duration of action of formoterol may extend up to $24 \mathrm{~h}$ when administered in a dose of $12 \mu \mathrm{g}$ every other day. The same effect was not evident with daily treatment. 


\section{Davis et al}

The acute bronchodilator properties of $12 \mu \mathrm{g}$ formoterol, measured as the absolute delta $\mathrm{FEV}_{1}$ from baseline to $10 \mathrm{~min}$ after treatment, were significantly less pronounced following $12 \mu \mathrm{g}$ daily formoterol administration, signifying possible loss of bronchodilation, which was not seen with thrice weekly treatment. Of clinical importance is the timeframe in which this loss occurs with daily treatment. The most pronounced loss in the delta $\mathrm{FEV}_{1}$ over the study period occurred with the second dose (Table 2). This partially recovered at the third dose, but the difference in delta $\mathrm{FEV}_{1}$ remained significant when compared with the first dose (within-group paired $t$ test). In fact, all measurements of delta $\mathrm{FEV}_{1}$ were significantly lower than those of the first dose within the daily treatment group; the day 8 delta $\mathrm{FEV}_{1}$ was significantly lower for daily versus

\section{REFERENCES}

1. Cockcroft DW, Swystun VA. Functional antagonism: tolerance produced by inhaled $\beta_{2}$ agonists. Thorax 1996;51:1051-6.

2. Boulet L-P, Becker A, Berube D, et al. Canadian asthma consensus report, 1999. CMAJ 1999;161(11 Suppl):S1-61.

3. Lipworth B, Soong T, Devlin M, et al. Effects of treatment with formoterol on bronchoprotection against methacholine. Am J Med 1998;104:431-8.

4. Juniper ER, Cockcroft DW, Hargreave FE. Histamine and Methacholine Inhalation Tests: Tidal Breathing Method Laboratory Procedure and Standardisation, 2nd edn. Lund: AB Draco, 1994.

5. American Thoracic Society Standardization of Spirometry 1994 Update. Am J Respir Crit Care Med 1995;152;1107-36.

6. Jokic R, Davis EE, Cockcroft DW. Methacholine $\mathrm{PC}_{20}$ extrapolation. Chest 1998;114:1796-7.

7. Cockcroft DW, Murdock KY, Mink JT. Determination of histamine every other day treatments. However, post-formoterol $\mathrm{FEV}_{1}$ values did not differ significantly (Table 2 ).

We have shown that the long-acting beta 2 -agonist formoterol administered in a dose of $12 \mu \mathrm{g}$ thrice weekly for a period of seven days does not result in the development of tolerance to the bronchoprotective effects against the direct-acting stimulus methacholine. Although statistical significance was not reached, there does appear to be a trend toward a loss in bronchoprotection when the same dose is administered daily.

ACKNOWLEDGEMENTS: John K Reid is Moorehead Fellow, supported by the Saskatchewan Lung Association; Donald W Cockcroft is Ferguson Professor, supported by the Saskatchewan Lung Association.

$\mathrm{PC}_{20}$ : comparison of linear and logarithmic interpolation. Chest 1983;84:505-6.

8. Lipworth BJ, Dempsey OJ, Aziz I. Functional antagonism with formoterol and salmeterol in asthmatic patients expressing the homozygous glycine-16 $\beta_{2}$-adrenoceptor polymorphism. Chest 2000;118:321-8.

9. Lipworth BJ, Aziz I. A high dose of albuterol does not overcome bronchoprotective subsensitivity in asthmatic subjects receiving regular salmeterol or formoterol. J Allergy Clin Immunol 1999;103:88-92.

10. Kalra S, Swystun VA, Bhagat R, et al. Inhaled corticosteroids do not prevent the development of tolerance to the bronchoprotective effect of salmeterol. Chest 1996;109:953-6.

11. Grootendorst DC, Sterk PJ, Heijerman HGM. Effect of oral prednisolone on the bronchoprotective effect of formoterol in patients with persistent asthma. Eur Respir J 2001;17:374-9. 


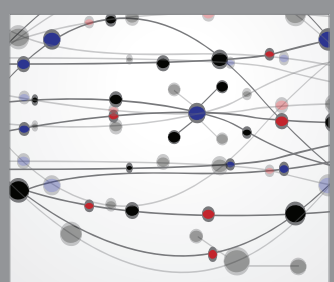

The Scientific World Journal
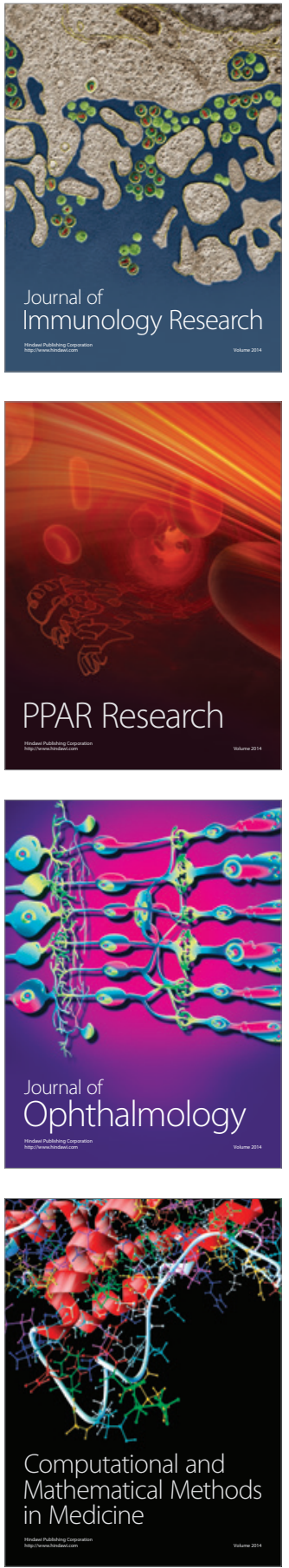

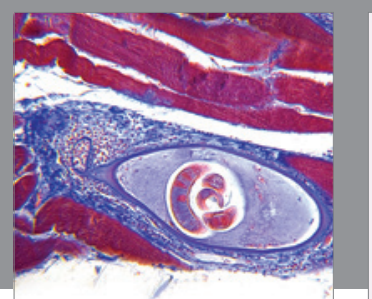

Gastroenterology Research and Practice

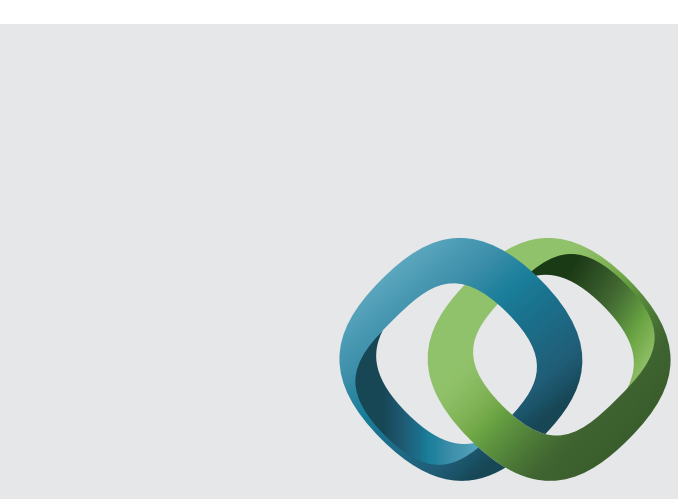

\section{Hindawi}

Submit your manuscripts at

http://www.hindawi.com
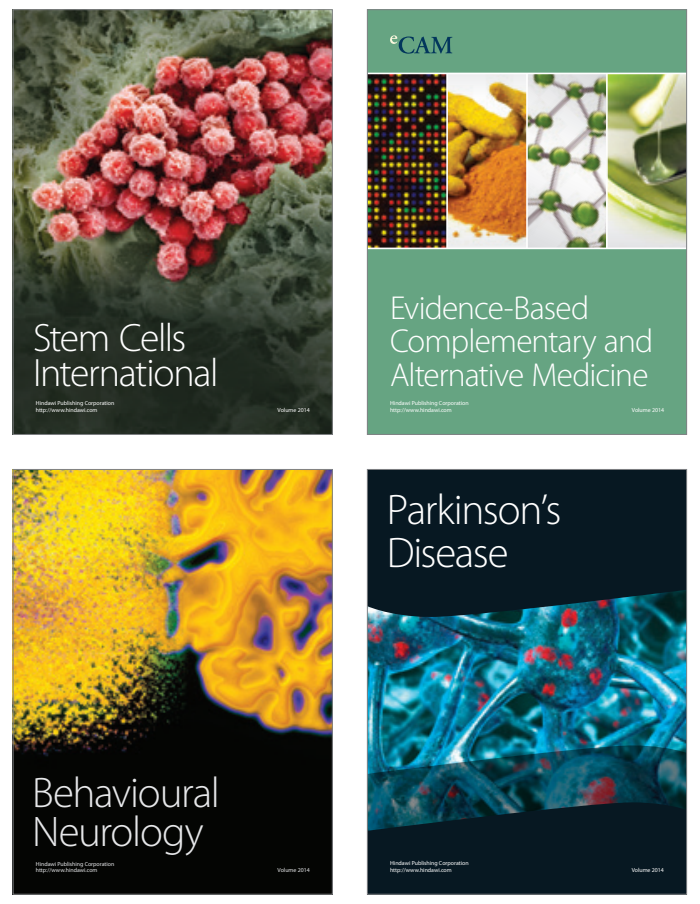
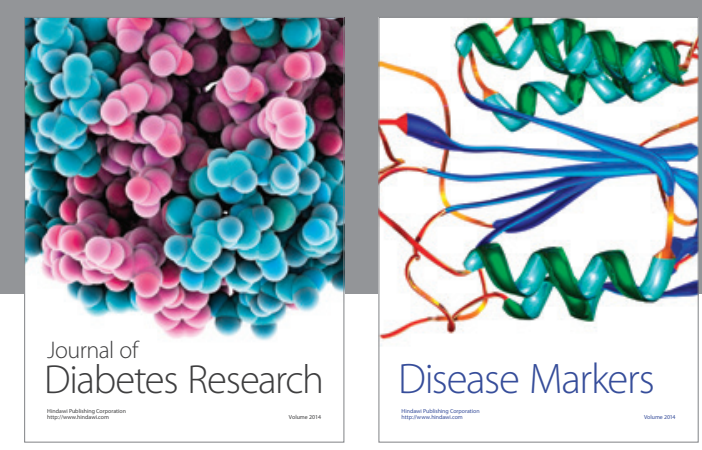

Disease Markers
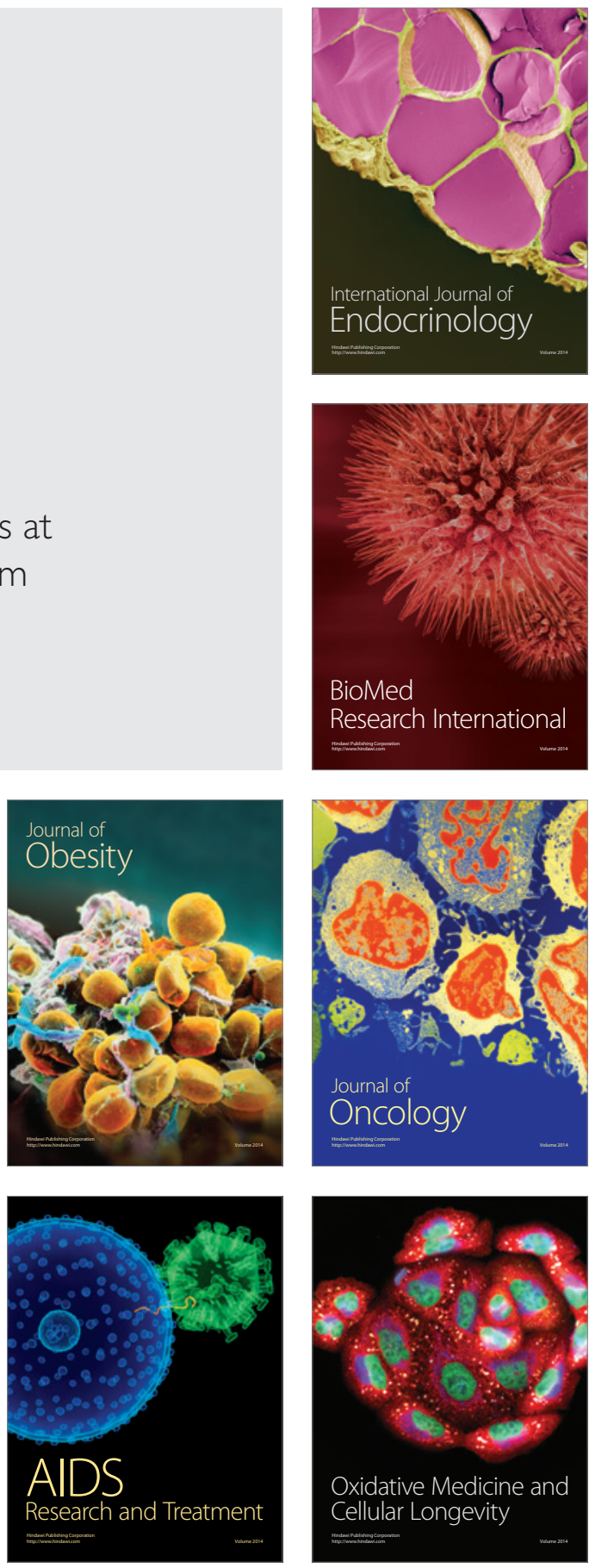